\title{
Serotonin-Related Gene Polymorphisms and Central Nervous System Serotonin Function
}

\author{
Redford B Williams*,', Douglas A Marchuk2 ${ }^{2}$ Kishore M Gadde', John C Barefoot', Katherine Grichnik ${ }^{3}$, \\ Michael J Helms', Cynthia M Kuhn ${ }^{4}$, James G Lewis ${ }^{5}$, Saul M Schanberg ${ }^{4}$, Mark Stafford-Smith ${ }^{3}$, Edward C \\ Suarez', Greg L Clary', Ingrid K Svenson' ${ }^{2}$ and Ilene C Siegler' \\ 'Department of Psychiatry and Behavioral Sciences, Duke University Medical Center, USA; '2Department of Genetics, Duke University Medical \\ Center, USA; ${ }^{3}$ Department of Anesthesiology, Duke University Medical Center, USA; ${ }^{4}$ Department of Pharmacology and Cancer Biology, Duke \\ University Medical Center, USA; ${ }^{5}$ Department of Pathology, Duke University Medical Center, USA
}

\begin{abstract}
Central nervous system (CNS) serotonergic function affects a wide range of biological and behavioral functions affecting health and disease. Our objective in this study was to determine whether functional polymorphisms of the genes that encode for the serotonin transporter promoter (5HTTLPR) and monoamine oxidase A (MAOA-uVNTR) are associated with CNS serotonin turnover-indexed by cerebrospinal fluid levels of 5-hydroxyindoleacetic acid (5-HIAA) - in a community sample of healthy adults. Subjects were 165 community volunteers without current medical or psychiatric illness, stratified with respect to ethnicity, gender, and socioeconomic status who underwent inpatient evaluation in the General Clinical Research Center of a university medical center. A significant ethnicity $\times$ genotype interaction $(P=0.008)$ indicated that, compared to the long/long and long/short genotypes, the 5HTTLPR short/short genotype was associated with higher CSF 5-HIAA levels in African Americans, but with lower levels in Caucasians. A gender $\times$ genotype interaction $(P=0.04)$ indicated that 5 HTTLPR short/short genotype was associated with higher 5-HIAA levels in women but with lower levels in men. MAOA-uVNTR 3.5 and 4 repeat alleles were associated with higher 5-HIAA $(P=0.03)$ levels in men, but were unrelated to 5-HIAA levels in women. These findings suggest that effects of serotonin-related gene polymorphisms on CNS serotonergic function vary as a function of both ethnicity and gender. Further research will be required to determine the mechanism(s) underlying these differential effects. In the meanwhile, both ethnicity and gender should be taken into account in research evaluating effects of these and related polymorphisms on CNS serotonergic function, as well as the broad range of biological and behavioral functions that are regulated by CNS serotonergic function.

Neuropsychopharmacology (2003) 28, 533-54I. doi:I 0.I 038/sj.npp. I 300054
\end{abstract}

Keywords: serotonin; 5HTTLPR; CSF 5-HIAA; ethnicity; gender; socioeconomic status

\section{INTRODUCTION}

The neurotransmitter serotonin is involved in the regulation of a broad array of psychological, behavioral, and biological functions that when dysregulated influence the development and course of an equally broad range of psychiatric and medical disorders. Low central nervous system (CNS) serotonergic function has been implicated, for example, in the mediation of negative emotions, impulsive aggressive

Supported by National Heart, Lung, and Blood Institute Grant POIHL36587, National Institute of Mental Health Grant K05MH79482, Clinical Research Unit Grant M0IRR30, and the Duke University Behavioral Medicine Research Center.

* Correspondence: Dr RB Williams, Department of Psychiatry and Behavioral Sciences, Duke University Medical Center, Box 3926, Durham, NC 277I0, USA, Tel: + I 919684 3863, Fax: + I 919681 8960, E-mail: redfordw@acpub.duke.edu

Received 9 August 2002; accepted 16 August 2002

Online publication: 29 August 2002 at http://www.acnp.org/citations/ Npp082902373 behavior, increased use of alcohol and nicotine, increased food consumption, increased sympathetic and decreased parasympathetic nervous system outflow, and altered neuroendocrine function (Williams, 1994, 1998). Peripherally, serotonin receptors and its transporter on platelets (Greenberg et al, 1999), immune system cells (Mossner and Lesch, 1998), cardiovascular system cells (Villalon and Saxena, 1997), and gastrointestinal system cells (Gershon, 1999) play an important role in regulating the functions of these organs and systems. These broad-ranging effects of serotonin have led to the hypothesis that altered CNS serotonergic function is a driver of the clustering of negative moods, risky health behaviors, and altered biological functions that increase disease risks in certain individuals and groups - for example, lower socioeconomic status (SES) (Williams, 1994, 1998).

Serotonergic function in both the CNS and peripheral organs, tissues and cells is determined by complex interactions among proteins involved in the enzymatically mediated synthesis of serotonin from its amino acid 
precursor tryptophan, its reuptake after release, its enzymatically mediated breakdown, and its effects on a large family of receptors on pre- and postsynaptic neurons as well as cells in other tissues and organs. Many of the genes encoding for these proteins have now been identified and cloned, and a growing body of research has begun to evaluate effects of variation in these candidate genes, in the form of polymorphisms, on the functions influenced by the encoded proteins.

The most intensively studied of these polymorphisms has been a 44-base pair insertion/deletion polymorphism (5HTTLPR) in the $5^{\prime}$ flanking regulatory region of the serotonin transporter gene $(17 \mathrm{q} 11.1-\mathrm{q} 12)$ that is associated with differential transcriptional efficiencies: both basal and stimulated activity of the long (L) allele is approximately twice that of the short (S) variant (Lesch et al, 1996). An initial report showing the $S$ allele to be associated with increased levels of neuroticism and decreased levels of agreeableness (assessed by the NEO Personality Inventory: NEO-PI) in a predominantly male Caucasian sample (Lesch et al, 1996) has not been replicated in several succeeding studies (Flory et al, 1999; Gusavsson et al, 1999). This failure to replicate the 5HTTLPR effects on personality dimensions may be explained by reports showing that gender and ethnicity moderate effects of 5HTTLPR genotypes on negative mood indices, with the $S$ allele associated with higher negative moods in men and/or Caucasians but associated with no effect or lower negative mood levels in women and/or other ethnic groups (Gelernter et al, 1998; Du et al, 2000). It should be noted, however, that a recent study did replicate the association of the $S$ allele with higher neuroticism and lower agreeableness in a female sample and showed the association not to be the result of population stratification (Greenberg et al, 2000).

Another source of variability in findings across studies of different populations is the observed variation in the frequency of the L allele across populations - ranging from more than $70 \%$ in Africa and African Americans to $50 \%$ in Europeans to less than $30 \%$ in Japan (Gelernter et al, 1999). This frequency variation could be associated with differences in allele effects. For example, the 5HTTLPR $S$ allele has been found to be associated with smoking behavior, via interaction with neuroticism, in Caucasian samples (Lerman et al, 2000; Hu et al, 2000), but a recent study found the $\mathrm{L}$ allele to be associated with smoking among Japanese males (Ishikawa et al, 1999). Similarly, while the S allele is associated with early-onset alcoholism and impulsive violent behavior in European samples (Hammoumi et al, 1999; Hallikainen et al, 1999), in a Japanese population it was the L allele that was found associated with alcoholrelated antisocial behavior (Ishiguro et al, 1999).

Furthermore, negative moods, alcohol abuse, and smoking are functions that are complexly determined, not by a single gene or specific environmental stimulus, but by the effects of multiple genes interacting with each other and with multiple aspects of the environment over time. It should come as no surprise, therefore, that factors like gender, ethnicity, and population are associated with differences in the effects of polymorphisms of serotoninrelated genes on mood and behavior.

One approach to clarifying how genetic variation in the serotonergic system affects the broad range of psychologi- cal, behavioral, and biological functions regulated by serotonergic function is to move 'upstream' from these complexly determined characteristics and assess the effects of polymorphisms of serotonin-related genes on more direct biological indices of serotonergic function. CSF 5hydroxyindoleacetic acid (5-HIAA) levels provide such a measure with respect to CNS serotonin turnover, especially reflecting activity in the frontal cortex (Stanley et al, 1985; Doudet et al, 1995). Low CNS serotonin function, as indexed by CSF 5-HIAA, is under both genetic and environmental control and correlates with impulsive and aggressive behaviors, as well as tendencies toward alcohol abuse, in nonhuman (Higley and Linnoila, 1997) and human primates (Roy et al, 1988; Ballenger et al, 1979). We recently reported (Williams et al, 2001) that persons with one or two copies of the 5HTTLPR L allele have CSF 5-HIAA levels that are 50\% higher than those in persons with the S/S genotype, an association that was not found, however, in a Swedish sample (Jonsson et al, 1998).

Research focusing on a functional polymorphism of another candidate gene known to influence serotonergic function illustrates further the importance of sample demographic characteristics in affecting associations between serotonin-related gene polymorphisms and CSF 5HIAA. A polymorphism (MAOA-uVNTR) in the upstream regulatory region of the gene encoding for monoamine oxidase A (MAOA), the enzyme that deaminates serotonin and norepinephrine, contains a variable number $-2,3,3.5$, 4 , or 5-of upstream tandem repeats (uVNTR) and has been shown to affect the transcriptional efficiency of the gene, in that alleles with 3.5 or 4 copies of the repeat sequence are transcribed 2-10 times more efficiently than those with 2, 3, or 5 copies of the repeat (Sabol et al, 1998). The more efficient 3.5 and 4 repeat MAOA-uVNTR alleles have been associated with higher levels of aggressiveness/ impulsivity and smaller CNS serotonergic responsivity (indexed by prolactin response to fenfluramine) in one study (Manuck et al, 2000). Another study found gender differences in the effect of MAO-uVNTR genotypes on CNS serotonin turnover, with the more efficient 3.5 and 4 alleles associated with higher CSF 5-HIAA levels in women, but with a nonsignificant trend toward lower levels in men (Jonsson et al, 2000).

In the context of an investigation of the role of CNS serotonergic turnover (indexed by CSF 5-HIAA levels) in the clustering of psychosocial and biobehavioral risk characterstics in lower SES groups, we have recruited a large sample of healthy community volunteers, with approximately equal proportions of men and women, African Americans and Caucasians, and high and low SES individuals, who undergo extensive testing during the course of a 2-day admission to the Duke General Clinical Research Center. We have also genotyped these subjects with respect to the 5HTTLPR and MAOA-uVNTR polymorphisms, making it possible to evaluate the impact of these polymorphisms on CNS serotonin turnover. The unique nature of our sample-a healthy community volunteer cohort that is stratified for ethnicity, gender, and SES - makes it possible for us to determine whether the ethnicity and gender moderation of the effects of these polymorphisms on 'soft' behavioral measures is also found for a more objective biological measure, CSF 5-HIAA. 
We report that both the 5HTTLPR and MAOA-uVNTR polymorphisms are associated with CSF 5-HIAA levels, but in ways that vary as a function of gender, ethnicity, and SES.

\section{METHODS}

\section{Subjects}

Subjects were admitted to the General Clinical Research Center (GCRC) at the Duke University Medical Center for a 2.5-day protocol that included lumbar puncture to obtain CSF, followed by randomization to either CNS serotonin enhancement (using tryptophan infusion) or CNS serotonin depletion (using tryptophan depletion) arms, with sham infusion or depletion on the first test day followed by active depletion or infusion on the second test day. Subjects also underwent mental stress testing at the point of expected maximal serotonin enhancement or depletion, with monitoring of cardiovascular function and collection of blood samples to assess neuroendocrine and immune system parameters. Results relating to serotonin manipulations and responses to stress testing will be the subject of subsequent communications.

Subjects were recruited via advertisements in the public media, inclusion in the community newsletter as part of the county water bill, flyers posted throughout the community, via outreach screening events at civic organizations and other public events, and in paid advertisements such as the back of supermarket tapes. This protocol required that subjects not be at risk because of the study procedures and that subject characteristics not hamper interpretation of the findings, making it important to ensure a sample population in good current health. Therefore, all subjects underwent a comprehensive examination using a modified SCID (by KMG or GLC) as well as medical history, physical exam, electrocardiogram, chest radiograph, hemoglobin, hematocrit, white cell count, and blood chemistries to rule out current psychiatric and medical disorders. Use of any prescription drugs as well as use of illegal drugs (as detected by a urine screen prior to entry into study) were grounds for exclusion.

As shown in Table 1, the final sample consisted of 165 subjects with 98 high (annual income $>\$ 24900$ or college degree) and 67 low (annual income $\leqslant \$ 24900$ and no college degree) SES, 91 male and 74 female, and 94 African American and 71 Caucasian (based on self-description) subjects. The stringent medical and psychiatric screening requirements made it harder for lower SES and women volunteers to qualify for the study.

A form approved by the Duke University Medical Center Institutional Review Board was used to obtain informed consent from all subjects.

\section{Procedures}

Subjects reported to the GCRC during the early afternoon. After completing admission procedures, and without a period of bed rest, lumbar puncture was performed by a board-certified anesthesiologist (KG or MS-S). Initially, as in published studies (Higley and Linnoila, 1997; Ballenger et al, 1979), we obtained 10-12 ml of CSF, which was mixed (to abolish the expected gradient across successive samples during the collection) and then separated into 2-ml aliquots and frozen for later assay of monoamine metabolites. The unsurprising $10-15 \%$ incidence of post-tap headaches among the first female subjects led us to determine whether there was a gradient of 5-HIAA levels across aliquots in the next two subjects. There was no gradient, with 5-HIAA concentrations in 11-12 $\mathrm{ml}$ being virtually identical to those in 1-2 ml. A previous study (Nordin et al, 1996) showed that without strict bed rest prior to the lumbar puncture, body height is unrelated to CSF 5-HIAA levels. Since our subjects had been ambulatory prior to lumbar puncture, it appears that CSF in the lumbar column had been mixed by their movements, thereby abolishing any gradient because of height. Therefore, we used a smaller needle to obtain only 3-4 $\mathrm{ml}$ of CSF, thereby preventing post-tap headaches. To ensure that findings are not affected by height differences, however, in all analyses evaluating effects of genotypes on CSF 5-HIAA levels we report results with and without control for height.

\section{Measures}

For genotyping of serotonin-related genes, genomic DNA was extracted by standard procedure (Puregene D-50K Isolation Kit, Gentra, Minneapolis, MN) from fresh or frozen samples of peripheral blood collected from the subjects. Polymerase chain reaction amplification to generate a 484- or 528-base pair fragment corresponding to the short (S) and long (L) 5HTTLPR alleles, respectively, was carried out as described elsewhere (Lesch et al, 1996).

Table I Demographic Characteristics of the Study Population $(N=165)$

\begin{tabular}{|c|c|c|c|c|c|c|c|c|}
\hline & \multicolumn{8}{|c|}{ Groups (defined by ethnicity, gender, and SES) } \\
\hline & AA/F/H & AA/F/L & AA/M/H & AA/M/L & W/F/H & W/F/L & W/M/H & W/M/L \\
\hline N & 24 & 18 & 25 & 27 & 23 & 9 & 26 & 13 \\
\hline Age, mean/SD (years) & $32.8 / 8.9$ & $30.3 / 9.1$ & $32.1 / 7.9$ & $33.0 / 9.5$ & $35.2 / 7 / 5$ & $36.4 / 7.6$ & $38.2 / 7.3$ & $34.5 / 9.1$ \\
\hline Household income mean/SD (I000's) & $39.9 / 20.9$ & 18.3/7.9 & $36.5 / 22.3$ & |7.9/7.9 & $47.1 / 24.2$ & $18.6 / 10.4$ & $44.5 / 23.0$ & $21.3 / 9.0$ \\
\hline Education, mean/SD (years) & $14.9 / 1.9$ & $12.7 / 1.8$ & |4.8/2.3 & $12.8 / 2.0$ & $17.1 / 1.9$ & |3.0/I.1 & 16.3/2.7 & $12.8 / 1.5$ \\
\hline Mother's education, mean/SD (years) & | 3.7/3.7 & $13.4 / 2.2$ & $12.7 / 3.1$ & | 3.0/2.2 & | $4.4 / 2.9$ & $10.6 / 2.7$ & $14.1 / 2.7$ & 13.3/2.3 \\
\hline Father's education, mean/SD (years) & $12.7 / 4.2$ & $12.3 / 4.2$ & $12.0 / 4.6$ & $12.4 / 3 / 3$ & $|4.5 / 4|$. & 10.3/3.0 & | $4.6 / 3.6$ & |2.5/4.0 \\
\hline Body mass index, mean/SD & $27.5 / 4.4$ & $27.7 / 8.8$ & $25.4 / 5.6$ & $27.1 / 5.5$ & $25.0 / 5.3$ & $26.0 / 5.4$ & $25.9 / 3.7$ & $26.0 / 1.9$ \\
\hline CSF 5-HIAA, mean/SD (ng/ml) & $20.5 / 9.5$ & 20.6/9.1 & |5.0/5.6 & 18.2/6.6 & 19.6/8.3 & 16.6/5.9 & $16.2 / 7.4$ & |5.9/7.3 \\
\hline
\end{tabular}

SES: Socioeconomic status; AA: African American; W: Caucasian; F: female; M: male; H: high SES; L: low SES. 
MAOA-uVNTR genotyping was carried out as described by Deckert et al (1999).

5-HIAA was measured by high-pressure liquid chromatography (HPLC) with electrochemical detection. The method used is a trace-enrichment method that utilized sequential C-18 columns for sample cleanup and analytical separation (Doudet et al, 1995). Samples were diluted in $0.2 \mathrm{~N}$ PCA containing $0.5 \mathrm{mM}$ EDTA and $0.5 \mathrm{mM}$ sodium metabisulfite, and injected directly onto the HPLC. The sample is enriched on a C-18 precolumn using an aqueous mobile phase composed of $0.05 \mathrm{M}$ citrate, $0.05 \mathrm{M}$ dibasic sodium phosphate, $0.5 \mathrm{mM}$ EDTA at $\mathrm{pH}$ 3.5. Then the sample is eluted onto a Waters Spherisorb $3 \mu$ M ODS2 C-18 column with a mobile phase containing $4-8 \%$ acetonitrile in addition to the components of the enrichment mobile phase. Samples are detected by electrochemical detection, with a detector potential set at $+0.55 \mathrm{mV} v s \mathrm{Ag} / \mathrm{AgCl}$ reference electrode. Data are collected with a computerbased data collection system, and quantitated with the use of internal standard and external standard curves. The sensitivity of the assay is $0.5 \mathrm{ng} / \mathrm{sample}$, and values are reported as $\mathrm{ng} / \mathrm{ml}$.

\section{Statistics}

We approached the analyses of associations between serotonin-related gene polymorphisms and CNS serotonin turnover as moderated by ethnicity, gender, and SES from an exploratory perspective. As noted above, CNS serotonin function influences a broad array of psychological and biological functions that affect health and disease, making it important to understand how variation in genes known to influence serotonergic mechanisms affects CNS serotonin function. Rather than hypothesis testing, our objective in this report is primarily to describe the associations that are present in our rigorously defined diverse healthy community cohort sample, leaving for further research the testing of hypotheses that emerge from this descriptive effort. The prior research we reviewed provides a basis for expecting that ethnicity and gender will moderate gene effects on CNS serotonergic function. Moreover, following Rao and $\mathrm{Gu}$ (2002), we are more concerned, at this stage of efforts to define genetic influences on serotonin-mediated phenotypes, to minimize false negatives (ie 'missing true signals') than to avoid false positives. False positives can be corrected by further research, but false negatives can result in important 'real signals' being missed.

One-way ANOVA was used to compare CSF 5-HIAA levels in 5HTTLPR and MAOA-uVNTR genotype groups. For 5HTTLPR genotypes, we report results using all three possible genotypes - L/L, L/S, and $S / S$ - as well as two genotype groupings - $\mathrm{L} / \mathrm{L}$ and $\mathrm{L} / \mathrm{S} v s \mathrm{~S} / \mathrm{S}$ - because 5-HIAA levels appear similar in $\mathrm{L} / \mathrm{L}$ and $\mathrm{L} / \mathrm{S}$, both of which differ from S/S. For MAOA-uVNTR genotypes, we report results comparing subjects with either of the two more efficient alleles (3.5 or 4 repeats) to those having only the less efficient 3 or 5 repeat alleles. Since the MAOA gene is on the $\mathrm{X}$ chromosome (Xp11.23) (Jonsson et al, 2000), men will be hemizygous for $3.5 / 4$ vs $3 / 5$ repeat alleles. Given the phenomenon of suppression of one $\mathrm{X}$ chromosome by the other in women, we also analyze the effects of MAOAuVNTR among women using three genotype categorizations: (1) 3.5 or 4 on one $\mathrm{X}$ chromosome and 3.5 or 4 on the other; (2) 3.5 or 4 on one $X$ chromosome and 3 or 5 on the other; and (3) 3 or 5 on both X chromosomes. Two-way ANOVA was used to evaluate the interaction between the two polymorphisms in affecting CSF 5-HIAA levels, as well as the interactions of ethnicity, gender, and SES indices with the polymorphisms, both singly and in combination. Analyses were carried out adjusting separately for both age and height. Results are reported as means \pm standard deviations (SD) and were considered significant at $P<0.05$.

\section{RESULTS}

\section{HTTLPR}

Consistent with other studies (Gelernter et al, 1999), allele frequencies varied significantly as a function of ethnicity, with African Americans having $72 \% \mathrm{~L}$ alleles and $28 \%$ short alleles, compared to $60 \% \mathrm{~L}$ and $40 \% \mathrm{~S}$ alleles in Caucasians $\left(\chi^{2}=4.74,1 \mathrm{df}, P<0.05\right)$.

As shown in Table 2, there is a significant interaction between ethnicity and 5HTTLPR genotypes. Among African Americans, those with the S/S genotype have higher CSF 5HIAA than those with either L/L or L/S genotypes $(P=0.04$ and 0.007 , respectively). Conversely, among Caucasians those with the S/S genotype have lower 5-HIAA levels than those with either L/L or L/S genotypes $(P=0.09$ and 0.13 , respectively). 5-HIAA levels did not differ as a function

Table 2 CSF 5-HIAA Levels as a Function of Ethnicity and 5HTTLPR Genotype

\begin{tabular}{|c|c|c|c|c|c|c|}
\hline \multirow[b]{3}{*}{ Genotype } & \multicolumn{2}{|l|}{ Ethnicity } & \multicolumn{4}{|c|}{ Ethnicity $\times$ Genotype } \\
\hline & \multirow{2}{*}{$\begin{array}{l}\text { African American } \\
\text { CSF 5-HIAA }(\mathrm{ng} / \mathrm{ml})\end{array}$} & \multirow{2}{*}{$\begin{array}{l}\text { Caucasian } \\
\text { CSF 5-HIAA (ng/ml) }\end{array}$} & \multicolumn{2}{|c|}{ Three genotypes* } & \multicolumn{2}{|c|}{ Two genotypes** } \\
\hline & & & Age adj. & Ht adj. & Age adj. & Ht adj. \\
\hline$L / L$ & $\begin{array}{l}18.57 \pm 7.72 \\
N=46\end{array}$ & $\begin{array}{l}18.38 \pm 6.94 \\
N=28\end{array}$ & & & & \\
\hline L/S & $\begin{array}{l}16.50 \pm 6.17 \\
N=30\end{array}$ & $\begin{array}{l}17.59 \pm 8.38 \\
N=28\end{array}$ & $\begin{array}{l}F=5.17 \\
P=0.007\end{array}$ & $\begin{array}{l}F=4.98 \\
P=0.008\end{array}$ & $\begin{array}{l}F=9.65 \\
P=0.002\end{array}$ & $\begin{array}{l}F=9.34 \\
P=0.003\end{array}$ \\
\hline$S / S$ & $\begin{array}{l}25.22 \pm 9.44 \\
N=9\end{array}$ & $\begin{array}{l}14.82 \pm 7.15 \\
N=14\end{array}$ & & & & \\
\hline
\end{tabular}

5-HIAA levels are means $\pm S D$. *L/L, L/S, and $S / S$. *** $L / L$ or $L / S$ vs $S / S$ 
Table 3 CSF 5-HIAA Levels as a Function of Gender and 5HTTLPR Genotype

\begin{tabular}{|c|c|c|c|c|c|c|}
\hline \multirow[b]{3}{*}{ Genotype } & \multicolumn{2}{|l|}{ Gender } & \multicolumn{4}{|c|}{ Gender $\times$ Genotype } \\
\hline & \multirow{2}{*}{$\begin{array}{l}\text { Female } \\
\text { CSF 5HIAA } \\
(\mathrm{ng} / \mathrm{ml})\end{array}$} & \multirow{2}{*}{$\begin{array}{l}\text { Male } \\
\text { CSF 5HIAA } \\
(\mathrm{ng} / \mathrm{ml})\end{array}$} & \multicolumn{2}{|c|}{ Three genotypes* } & \multicolumn{2}{|c|}{ Two genotypes** } \\
\hline & & & Age adj. & Ht adj. & Age adj. & Ht adj. \\
\hline $\mathrm{L} / \mathrm{L}$ & $\begin{array}{l}19.26 \pm 8.34 \\
N=34\end{array}$ & $\begin{array}{l}17.85 \pm 6.45 \\
N=40\end{array}$ & & & & \\
\hline L/S & $\begin{array}{l}18.46 \pm 7.56 \\
N=22\end{array}$ & $\begin{array}{l}16.14 \pm 7 / 05 \\
N=36\end{array}$ & $\begin{array}{l}F=2.44 \\
P=0.09\end{array}$ & $\begin{array}{l}F=2.18 \\
P=0.12\end{array}$ & $\begin{array}{l}F=4.54 \\
P=0.03\end{array}$ & $\begin{array}{l}F=4.12 \\
P=0.04\end{array}$ \\
\hline$S / S$ & $\begin{array}{l}22.13 \pm 9.50 \\
N=15\end{array}$ & $\begin{array}{l}|2.8| \pm 5.80 \\
N=8\end{array}$ & & & & \\
\hline
\end{tabular}

5-HIAA levels are means $\pm S D$. *L/L, L/S, and S/S. **t/L or L/S vs S/S.

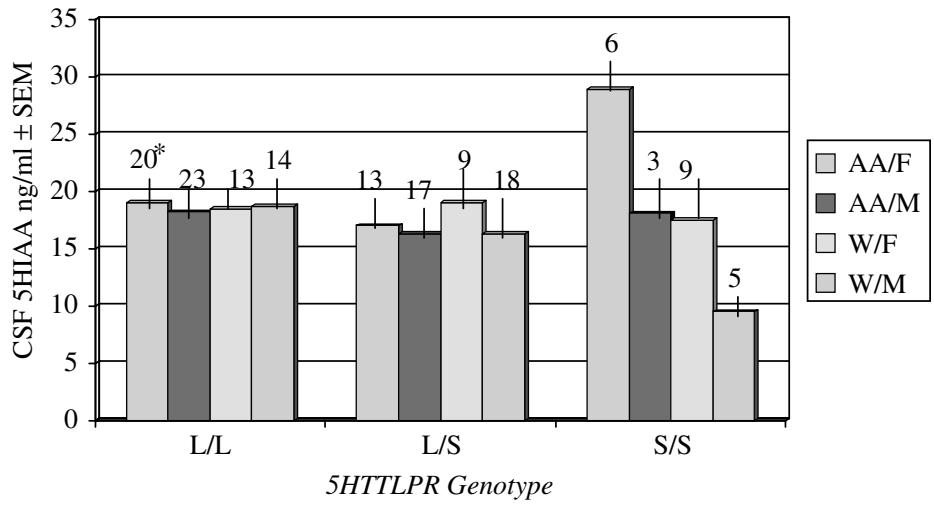

Figure I CSF 5-HIAA levels in four ethnicity $\times$ gender groups. Values shown are means \pm SEM. *Number of subjects in each ethnicity/gender group.

of $\mathrm{L} / \mathrm{L}$ or $\mathrm{L} / \mathrm{S}$ genotypes within or across ethnic groups (all $P$ 's $>0.22$ ), but the level in African Americans with the $S / S$ genotype was significantly higher $(P<0.003)$ than that in Caucasians with the $S / S$ genotype. These effects became slightly stronger when two genotypes were compared and were not affected by adjustments for age or height.

A less robust interaction - significant only in analyses modeling two genotypes - was found (Table 3) between gender and 5HTTLPR genotypes. Among women, those with the S/S genotype have higher 5-HIAA levels than those with either $\mathrm{L} / \mathrm{L}$ or $\mathrm{L} / \mathrm{S}$ genotypes $(P=0.26$ and 0.17 , respectively). Among men, those with the $S / S$ genotype had lower levels than those with either L/L or L/S genotypes $(P=0.08$ and 0.28 , respectively). Men and women with the $\mathrm{L} / \mathrm{L}$ or L/S genotypes showed 5-HIAA levels that did not differ significantly $(P$ 's $>0.26)$, but there was a trend $(P=0.10)$ for women with the $S / S$ genotype to have higher levels than men with the S/S genotype.

The ethnicity $\times$ gender $\times 5$ HTTLLPR genotype interaction was not significant $(P=0.49)$ with respect to CSF 5HIAA levels, indicating that the moderating effects of gender and ethnicity on 5HTTLPR effects on CNS serotonin turnover are independent of each other. These independent, but additive effects of ethnicity and gender can be appreciated by an inspection of Figure 1, where it can be seen that there are no differences in CSF 5-HIAA levels across the four ethnicity/gender groups with $\mathrm{L} / \mathrm{L}$ or $\mathrm{L} / \mathrm{S}$ genotypes. In marked contrast, among those with the S/S genotype, African-American women have very high 5-HIAA levels, and Caucasian men have very low levels, while African-American men and Caucasian women have levels that do not differ from each other or from any of the $\mathrm{L} / \mathrm{L}$ or L/S subjects.

In addition to ethnicity and gender, we also performed analyses evaluating interactions between 5HTTLPR genotype and various indices of SES. When subjects' SES was used, there was no indication of an SES $\times 5$ HTTLPR genotype interaction, nor of three-way interactions involving SES and ethnicity or gender. Prior research has shown, however, that SES during childhood can exert effects on adult psychosocial characteristics that are independent of current SES (Lynch et al, 1997). Moreover, it has been shown in nonhuman primates that the 5HTTLPR polymorphism is associated with CSF 5-HIAA levels, but only among animals subjected to maternal deprivation during the first 6 months of life; among mother-reared animals 5HTTLPR genotypes were unrelated to 5-HIAA levels (Bennett et al, 2002). Therefore, two further analyses evaluated effects on 5-HIAA levels of the interaction between a measure of our subjects' childhood environments, indexed by their mothers' and fathers' formal educational attainments, and 5HTTLPR genotypes.

These analyses did not reveal significant interactions between 5HTTLPR genotypes and parental education levels in predicting CSF 5-HIAA levels. Interactions involving gender, parental education levels, and 5HTTLPR genotypes 
were also not significant. However, there was a nonsignificant trend (shown for mother's education level in Table 4; similar effects were found for father's education level) toward an ethnicity $\times$ parental education $\times 5$ HTTLPR genotype interaction, particularly when two levels of 5HTTLPR genotypes were used. Despite the absence of a significant interaction, the prior observation (Bennett et al, 2002) in rhesus monkeys of an effect of 5HTTLPR genotypes on CSF 5-HIAA levels only among those subjected to the early adversity of maternal separation during the first 6 months of life led us to examine the levels in these groups.

As can be appreciated from an inspection of Table 4, the opposite effects of the S/S genotype on 5-HIAA levels in African Americans and Caucasians reported above are more pronounced among African Americans and Caucasians whose parents had 12 years of education or less. That is, there are no differences in 5-HIAA levels across the three genotypes in African Americans (all $P^{\prime} s>0.39$ ) or Caucasians (all $P$ 's $>0.28$ ) whose parents had more than 12 years of education. In contrast, among African-American subjects whose mother had less than 12 years of education, those with the S/S genotype had 5-HIAA levels that were higher than those with $\mathrm{L} / \mathrm{L}$ or $\mathrm{L} / \mathrm{S}$ genotypes $(P<0.03$ and 0.01 , respectively). Among Caucasian subjects whose mothers had less than 12 years of education, those with the S/S genotype had lower 5-HIAA levels than those with $\mathrm{L} / \mathrm{L}$ or $\mathrm{L} /$ $S$ genotypes ( $P=0.09$ and 0.21 , respectively). Similar results were obtained in analyses using the father's education level. Given the small cell sizes, these effects must be interpreted with caution and should only be considered as exploratory.

\section{MAOA-uVNTR}

Allele frequencies in Caucasians were $34 \%$ (3 repeats), $4 \%$ (3.5 repeats), $60 \%$ (4 repeats), and $2 \%$ (5 repeats), which do not differ $\left(\chi^{2}=3.83,4 \mathrm{df}, P>0.25\right)$ from the frequencies reported in a Swedish sample (Jonsson et al, 2000). Among African Americans, however, the allele frequencies differed significantly $\left(\chi^{2}=42.33,4 \mathrm{df}, P<0.005\right)$ from those in the Swedish sample, with African Americans having a lower frequency $(56 \%)$ of the 3.5 or 4 repeat alleles than Caucasians (75\%).

Since the MAOA gene is located on the $\mathrm{X}$ chromosome, following Jonsson et al (2000), each gender was analyzed separately. There were no significant effects of MAOAuVNTR genotypes on CSF 5-HIAA as a function of ethnicity. As shown in Table 5, however, males with either the 3.5 or 4 repeat alleles had significantly higher CSF 5HIAA levels than those with other alleles. Among females, no association was found between MAOA-uVNTR genotypes and 5-HIAA levels. Similar effects were found in separate analyses for the two ethnic groups.

\section{MAOA-uVNTR and 5HTTLPR Combined Effects}

Small cell sizes provided inadequate power to evaluate associations between MAOA-uVNTR and 5HTTLPR genotypes in either of the four ethnicity/gender subgroups. In the overall sample there was a nonsignificant trend $\left(\chi^{2}=2.89,1 \mathrm{df}, P=0.09\right)$ for the 5HTTLPR S/S genotype to be more frequent in subjects with the MAOA-uVNTR 3.5/

Table 4 CSF 5-HIAA Levels (ng/ml) as a Function of Ethnicity, Mother's Education, and 5HTTLPR Genotype

\begin{tabular}{|c|c|c|c|c|c|c|c|c|}
\hline \multirow[b]{3}{*}{ M. Educ. } & \multicolumn{4}{|l|}{ Ethnicity } & \multicolumn{4}{|c|}{ Ethnicity $\times$ M. educ. $\times$ genotype } \\
\hline & \multicolumn{2}{|c|}{ African-American } & \multicolumn{2}{|l|}{ Caucasian } & \multicolumn{2}{|c|}{ Three genotypes* } & \multicolumn{2}{|c|}{ Two genotypes** } \\
\hline & $>12$ years & $\leqslant 12$ years & $>12$ years & $\leqslant 12$ years & Age adj. & Ht adj. & Age adj. & Ht adj. \\
\hline$L / L$ & $\begin{array}{l}19.08 \pm 8.34 \\
N=23\end{array}$ & $\begin{array}{l}16.76 \pm 6.53 \\
N=22\end{array}$ & $\begin{array}{l}17.54 \pm 7.98 \\
N=14\end{array}$ & $\begin{array}{l}19.21 \pm 5.89 \\
N=14\end{array}$ & & & & \\
\hline$L / S$ & $\begin{array}{l}17.06 \pm 6.74 \\
N=12\end{array}$ & $\begin{array}{l}|5.6| \pm 5.58 \\
N=16\end{array}$ & $\begin{array}{l}17.98 \pm 9.34 \\
N=15\end{array}$ & $\begin{array}{l}17.83 \pm 7.33 \\
N=12\end{array}$ & $\begin{array}{l}F=1.49 \\
P=0.23\end{array}$ & $\begin{array}{l}F=0.099 \\
P=0.38\end{array}$ & $\begin{array}{l}F=2.94 \\
P=0.09\end{array}$ & $\begin{array}{l}F=1.92 \\
P=0.17\end{array}$ \\
\hline$S / S$ & $\begin{array}{l}21.18 \pm 6.03 \\
N=4\end{array}$ & $\begin{array}{l}27.78 \pm 12.60 \\
N=4\end{array}$ & $\begin{array}{l}15.60 \pm 8.36 \\
N=9\end{array}$ & $\begin{array}{l}13.42 \pm 4.75 \\
N=5\end{array}$ & & & & \\
\hline
\end{tabular}

5-HIAA levels are means $\pm \mathrm{SD}$. *L/L, L/S, and S/S. *** LL or L/S vs S/S.

Table 5 CSF 5-HIAA Levels in Males and Females as a Function of MAOA-uVNTR Genotype

\begin{tabular}{|c|c|c|c|c|c|c|}
\hline \multirow[b]{2}{*}{ Genotype } & \multicolumn{3}{|l|}{ Males } & \multicolumn{3}{|l|}{ Females } \\
\hline & CSF 5-HIAA & Age adj. & Ht adj. & CSF 5-HIAA & Age adj. & Ht adj. \\
\hline $3.5 / 4$ & $\begin{array}{l}17.70 \pm 7.30 \\
N=48\end{array}$ & & & $\begin{array}{l}19.90 \pm 8.53 \\
N=50\end{array}$ & & \\
\hline Other & $\begin{array}{l}14.34 \pm 5.27 \\
N=36\end{array}$ & $\begin{array}{l}F=5.29 \\
P=0.02\end{array}$ & $\begin{array}{l}F=4.7 I \\
P=0.03\end{array}$ & $\begin{array}{l}20.16 \pm 8.09 \\
N=18\end{array}$ & $\begin{array}{l}F=0.01 \\
P=0.91\end{array}$ & $\begin{array}{l}F=0.00 \\
P=0.96\end{array}$ \\
\hline $3.5 \& 4$ & & & & $\begin{array}{l}19.00 \pm 7.16 \\
N=24\end{array}$ & & \\
\hline 3.5 or 4 & & & & $\begin{array}{l}20.73 \pm 9.33 \\
N=26\end{array}$ & & \\
\hline Other & & & & $\begin{array}{l}20.16 \pm 8.09 \\
N=18\end{array}$ & $\begin{array}{l}F=0.27 \\
P=0.77\end{array}$ & $\begin{array}{l}F=0.19 \\
P=0.83\end{array}$ \\
\hline
\end{tabular}

5-HIAA levels are means \pm SD. 
4 genotype (17 vs $7 \%$ in those without 3.5 or 4 repeat alleles). The 5HTTLPR $\times$ MAOA-uVNTR interaction was not significant $(\mathrm{F}=0.11, P=0.74)$ in predicting the CSF 5HIAA level.

\section{DISCUSSION}

This study, the first to include a larger sample than previous studies of healthy young adults balanced for SES, ethnicity, and gender, found that functional polymorphisms of two candidate genes that play important roles in the regulation of serotonergic function are associated with variation in CNS serotonergic function as indexed by CSF 5-HIAA levels. The influence of these polymorphisms varies, however, as a function of both ethnicity and gender. The presumably less transcriptionally efficient 5HTTLPR S allele is associated, when homozygous, with higher 5-HIAA levels in African Americans, but with lower levels among Caucasian subjects. Among women, the S/S genotype is associated with higher 5-HIAA levels but with lower levels among men. As shown in Figure 1, these effects are independent but additive, with nonoverlapping distributions of 5-HIAA levels in African-American women and Caucasian men with the S/S genotype. In contrast, among African-American men and Caucasian women with the S/S genotype CSF 5-HIAA levels do not differ from those of all other ethnicity/gender groups with $\mathrm{L} / \mathrm{L}$ or $\mathrm{L} / \mathrm{S}$ genotypes. These findings suggest that failures to replicate prior associations between the $\mathrm{S} / \mathrm{S}$ genotype and personality factors could result from these striking differences as a function of ethnicity and gender of the S/S genotype on CNS serotonergic function.

As in our previous report on the initial 54 subjects in this project (Williams et al, 2001), we continue to find the L allele acting in a dominant fashion with respect to 5-HIAA levels - an effect similar to that found for the L allele's affect on clinical response to SSRI treatment in depressed patients (Smeraldi et al, 1998). The sample in our initial report contained too few African Americans or women with the S/S genotype to permit detection of the moderating effects of ethnicity and gender that are apparent with the larger sample now available. We also found the more efficient MAOA-uVNTR 3.5 and 4 repeat alleles associated with higher 5-HIAA levels, but, in contrast to Jonsson et al (2000), this association was present only in men in our study.

The mechanisms responsible for these differential effects of serotonin-related gene polymorphisms as a function of ethnicity and gender are not known at present. The strong ethnicity $\times 5$ HTTLPR genotype interaction could be the result of ethnic differences in linkage disequilibrium between the $S$ allele and other serotonin transporter gene polymorphisms, with linkage in one of the ethnic groups resulting in a reversal of the effect of the S/S genotype on serotonin turnover. It would be possible to confirm this explanation by sequencing the transporter gene in our subjects and documenting that in either African Americans or Caucasians the $S$ allele is linked to another locus that accounts for its opposite effects on 5-HIAA levels in these two groups. To our knowledge, the prior work documenting the increased transcriptional efficiency of the $\mathrm{L}$ allele has been done only in Caucasian samples, making it possible that in African-derived populations the $S$ allele could be in linkage disequilibrium with another locus that renders it more, rather than less, transcriptionally efficient. Consistent with this possibility are reports of ethnic differences in patterns of linkage disequilibrium between the 5HTTLPR and a similar polymorphism in intron 2 of the transporter gene, with the direction of linkage disequilibrium in an African population being opposite to that in two European samples (Gelernter et al, 1999).

Whatever the underlying mechanism, if our results are replicated in further studies and the opposite effects of the S/ $S$ genotype on CNS serotonin turnover in African Americans and Caucasians are confirmed, it could help to explain ethnic differences, not only with respect to effects of the 5HTTLPR on personality (Gelernter et al, 1998) but also, for example, in responsivity to drugs that act via the serotonergic system. African Americans with depression have been reported to have higher rates of nonresponse to SSRIs than Caucasians (Wagner et al, 1998), to be less likely to take antidepressants (Blazer et al, 2000), and to have poorer functional outcomes (Brown et al, 1999). While these ethnic differences in response to drug treatment could result from differences in rates of drug metabolism (Bradford and Kirlin, 1998; Sramek and Pi, 1996) and/or environmental factors (eg reduced access to medical care), it is possible that the opposite effect of the S/S genotype on an index of CNS serotonin turnover we find in African Americans compared to Caucasians is also playing a role. Illustrative of the potential importance of ethnic differences in the effects of 5HTTLPR genotypes on drug response is a study from Japan (Yoshida et al, 2002) where, in contrast to the European study that found the $S$ allele associated with slower response to fluvoxamine (Smeraldi et al, 1998), the $S$ allele was associated with higher response rates to fluvoxamine. Different effects of serotonin gene polymorphisms on CNS serotonin turnover in different ethnic groups, like the one we report here, could be an important factor in ethnic and population differences in response to serotonergic drugs.

It is tempting to ascribe the gender differences in effects of the 5HTTLPR polymorphism on 5-HIAA levels to the known effects of estrogen on the expression of genes involved in regulating the serotonin system. It has been shown that estrogen increases tryptophan hydroxylase gene mRNA (Pecins-Thompson et al, 1996) expression and decreases mRNA expression of both the serotonin transporter (Pecins-Thompson and Bethea, 1999) and $5 \mathrm{HT}_{1 \mathrm{~A}}$ autoreceptor (Pecins-Thompson et al, 1998) genes. These effects would be expected to produce increased serotonergic function in women, via increased synthesis and decreased termination of action via reuptake or stimulation of the inhibitory autoreceptor. The effects of estrogen to increase transporter gene expression could have effects on the S/S genotype that could account for the increased 5-HIAA levels that we observe in women with the S/S genotype. All women in this study were premenopausal. If estrogen is a factor, in postmenopausal women the effect of the S/S genotype to increase CSF 5-HIAA levels may be weaker.

Early life experiences, as indexed by parental education levels, appear to moderate the differential impact of the S/S genotype on 5-HIAA in different ethnic groups. Whatever the ultimate explanation turns out to be for the opposite effects of the 5HTTLPR S/S genotype on CSF 5-HIAA levels 
in African Americans and Caucasians, the trend for these effects to be more pronounced in subjects whose parents had a lower level of education (Table 4) suggests that early life experiences may moderate these differential effects of the $S / S$ genotype in the two ethnic groups. Small numbers of subjects with the $S / S$ genotype in our sample dictate caution in interpreting the observed trends prior to replication. There is some precedent for such moderation by early life experience of the effects of 5HTTLPR genotypes on CSF 5-HIAA levels, however. In a rhesus monkey model, it is only in those exposed to early adversity that 5HTTLPR genotypes affect CSF 5-HIAA levels measured later in life (Bennett et al, 2002).

This study has several limitations that should be noted. Most important is the limited sample size that prevented us from more detailed examinations of the joint effects of the two genes we studied. Despite our having a healthy sample balanced for both ethnicity and gender that is larger than in previous studies evaluating the effects of serotonin-related genes on CSF 5-HIAA, the sample size limitations dictate that we view the ethnicity, gender, and SES-related effects reported here as preliminary and subject to further replication and elaboration. Despite our having bases from prior research to evaluate ethnicity, gender, and SES indices as moderators of gene effects on CNS serotonin function, the number of tests that were done raises a legitimate concern that some of the findings reported here could be because of chance-Type I error. We are unaware of another sample as large as ours, with comparable numbers of different ethnic and gender groups, however, and believe that exploratory analyses are therefore warranted.

Several considerations highlight the importance of undertaking such research on a larger and more ambitious scale than heretofore. First, the importance of serotonergic effects on a wide array of psychological, behavioral, and biological characteristics involved in health and disease makes it essential that we increase our understanding of how variations in serotonin-related genes interact with each other, other genes, and the environment to affect these characteristics. Second, the already emerging evidence linking 5HTTLPR genotypes with increased CHD and lipids (Arinami et al, 1999; Comings et al, 1999; Fumeron et al, 2002) and important health behaviors like smoking (Lerman et al, 2000; Hu et al, 2000) suggests that such research is likely to increase our understanding of the bases of individual differences in susceptibility to disease. And third, the failure in some studies to replicate earlier reported associations between 5HTTLPR genotypes and, for example, personality traits could stem from the failure to take into account ethnic and gender differences in how 5HTTLPR genotypes are related to CNS serotonin turnover that are suggested by our findings. The current findings suggest that further research evaluating the effects of serotonin-related gene polymorphisms on a wide range of phenotypes should consider both ethnicity and gender as potential moderators of those effects.

\section{REFERENCES}

Arinami T, Ohtsuki T, Yamakawa-Kobayashi K, Amemiya H, Fujiwara H, Kawata $\mathrm{K}$ et al (1999). A synergistic effect of serotonin transporter gene polymorphism and smoking in association with CHD. Thromb Haemost 81: 853-856.

Ballenger J, Goodwin FK, Major LF, Brown GL (1979). Alcohol and central serotonin metabolism in man. Arch Gen Psychiatry 36: 224-227.

Bennett AJ, Lesch KP, Heils A, Long JC, Lorenz JG, Shoaf SE et al (2002). Early experience and serotonin transporter gene variation interact to influence primate CNS function. Mol Psychiatry 7: $118-122$

Blazer DG, Hybels CF, Simonsick EM, Hanlon JT (2000). Marked differences in antidepressant use by race in an elderly community sample. Am J Psychiatry 157: 1089-1094.

Bradford LD, Kirlin WG (1998). Polymorphism of CYP2D6 in Black populations: implications for psychopharmacology. Int J Neuropsychopharmacol 1: 173-185.

Brown C, Schulberg HC, Sacco D, Perel JM, Houck PR (1999). Effectiveness of treatments for major depression in primary medical care practice: a post hoc analyssis of outcomes for African American and white patients. J Affect Disord 53: 185-192.

Comings DE, MacMurray JP, Gonzalez N, Ferry L, Peters WR (1999). Association of the serotonin transporter gene with serum cholesterol levels and heart disease. Mol Genet Metabolism 67: 248-253.

Deckert J, Catalano M, Syagailo YV, Bosi M, Okladnova O, Di Bella $\mathrm{D}$ et al (1999). Excess of high activity monoamine oxidase A gene promoter alleles in female patients with panic disorder. Hum Mol Genet 8: 621-624.

Doudet D, Hommer D, Higley JD, Andreason PJ, Moneman R, Suomi SJ et al (1995). Cerebral glucose metabolism, CSF 5-HIAA levels, and aggressive behavior in rhesus monkeys. $A m$ J Psychiatry 152: 1782-1787.

Du L, Bakish D, Hrdina PD (2000). Gender differences in association between serotonin transporter gene polymorphism and personality traits. Psychiatr Genet 10: 159-164.

Flory JD, Manuck SB, Ferrell RE, Dent KM, Peters DG, Muldoon MF (1999). Neuroticism is not associated with the serotonin transporter (5-HTTLPR) polymorphism. Mol Psychiatry 4: 93-96.

Fumeron F, Betoulle D, Nicaud V, Evans A, Kee F, Ruidavets J-B et al (2002). Serotonin transporter gene polymorphism and myocardial infarction. Circulation 105: 2943-2945.

Gelernter J, Cubells JF, Kidd JR, Pakstis AJ, Kidd KK (1999). Population studies of polymorphisms of the serotonin transporter gene. Am J Med Genet (Neuropsychiatr Genet) 88: 61-66. Gelernter J, Kranzler H, Coccaro EF, Siever LJ, New AS (1998). Serotonin transporter protein gene polymorphism and personality measures in African American and European American subjects. Am J Psychiatry 155: 1332-1338.

Gershon MD (1999). Review article: roles played by 5-hydroxytryptamine in the physiology of the bowel. Aliment Pharmacol Ther 13(Suppl 2): 15-30.

Greenberg BD, Li Q, Lucas FR, Hu S, Sirota LA, Benjamin J et al (2000). Association between the serotonin transporter promoter polymorphism and personality traits in a primarily female population sample. Am J Med Genet (Neuropsychiatr Genet) 96: 202-216.

Greenberg BD, Tolliver TJ, Huang S-J, Li Q, Bengel D, Murphy DL (1999). Genetic variation in the serotonin transporter promoter region affects serotonin uptake in human platelets. Am J Med Genet (Neuropsychiatr Genet) 88: 83-87.

Gusavsson JP, Nothen MM, Jonsson EG, Neidt H, Foralund K, Rylander $G$ et al (1999). No association between serotonin transporter gene polymorphisms and personality traits. $A m J$ Med Genet 88: 430-436.

Hallikainen T, Saito T, Lachman HM, Volavka J, Pohjalainen T, Ryynanen OP et al (1999). Association between low activity serotonin transporter promoter genotype and early onset 
alcoholism with habitual impulsive violent behavior. Mol Psychiatry 4: 385-388.

Hammoumi S, Payen A, Favre JD, Balmes JL, Bernard JY, Husson $M$ et al (1999). Does the short variant of the serotonin transporter linked polymorphic region constitute a marker of alcohol dependence? Alcohol 17: 107-112.

Higley JD, Linnoila M (1997). Low central nervous system serotonergic activity is traitlike and correlates with impulsive behavior. A nonhuman primate model investigating genetic and environmental influences on neurotransmission. Ann NY Acad Sci 29: 39-56.

Hu S, Brody CL, Fisher C, Gunzerath L, Nelson ML, Sabol SZ et al (2000). Interaction between the serotonin transporter gene and neuroticism in cigarette smoking behavior. Mol Psychiatry 5: $181-188$

Ishiguro H, Saito T, Akazawa S, Mitushio H, Tada K, Enomoto M et al (1999). Association between drinking-related antisocial behavior and a polymorphism in the serotonin transporter gene in a Japanese population. Alcohol Clin Exp Res 23: 1281-4.

Ishikawa $\mathrm{H}$, Ohtsuki T, Ishiguro $\mathrm{H}$, Yamakawa-Kobayashi K, Endo $\mathrm{K}$, Lin YL et al (1999). Association between serotonin transporter gene polymorphism and smoking among Japanese males. Cancer Epidemiol Biomarkers Prev 8: 831-833.

Jonsson EG, Norton N, Gustavsson P, Oreland L, Owen MJ, Sedvall GC (2000). A promotoer polymorphism in the monoamine oxidase A gene and its relationships to monoamine metabolite concentrations in CSF of healthy volunteers. J Psychiatr Res 34: 39-244.

Jonsson EG, Nothen MM, Gustavsson JP, Neidt H, Bunzel R, Propping $\mathrm{P}$ et al (1998). Polymorphisms in the dopamine, serotonin, and norepinephrine transporter genes and their relationships to monoamine metabolite concentrations in CSF of healthy volunteers. Psychiatry Res 79: 1-9.

Lerman C, Caporaso NE, Audrain J, Main D, Boyd NR, Shields PG (2000). Interacting effects of the serotonin transporter gene and neuroticism in smoking practices and nicotine dependence. $\mathrm{Mol}$ Psychiatry 5: 189-192.

Lesch KP, Bengel D, Heils A, Sabol SZ, Greenberg B, Petri S et al (1996). Association of anxiety-related traits with a polymorphism in the serotonin transporter gene regulatory region. Science 274: 1527-1531.

Lynch JW, Kaplan GA, Salonen JT (1997). Why do poor people behave poorly? Variation in adult health behaviours and psychosocial characteristics by stages of the socioeconomic lifecourse. Soc Sci Med 44: 809-19.

Manuck SB, Flory JD, Ferrell RE, Mann JJ, Muldoon MF (2000). A regulatory polymorphism of the monoamine oxidase- $A$ gene may be associated with variability in aggression, impulsivity, and central nervous system serotonergic responsivity. Psychiatry Res 95: 9-23.

Mossner R, Lesch KP (1998). Role of serotonin in the immune system and in neuroimmune interactions. Brain Behav Immunity 12: 249-271.
Nordin C, Lindstrom L, Wieselgren IM (1996). Acid monoamine metabolites in the CSF of healthy controls punctured without preceding strict bedrest: a retrospective study. J Psychiatr Res 30: 127-133.

Pecins-Thompson M, Bethea CL (1999). Ovarian steroid regulation of serotonin-1A autoreceptor messenger RNA expression in the dorsal raphe of rhesus macaques. J Neurosci 89: 267-277.

Pecins-Thompson M, Brown NA, Bethea CL (1998). Regulation of serotonin re-uptake transporter mRNA expression by ovarian steroids in rhesus macaques. Brain Res Mol Brain Res 53: 120-129.

Pecins-Thompson M, Brown NA, Kohama SG, Bethea CL (1996). Ovarian steroid regulation of tryptophan hydroxylase mRNA expression in rhesus macaques. J Neurosci 16: 7021-7029.

Rao DC, Gu C (2002). Principles and methods in the study of complex phenotypes. In: Benjamin J, Ebstein RP, Belmaker RH (eds). Molecular Genetics and the Human Personality. American Psychiatric Publishing: Washington, DC. pp 1-32.

Roy A, Adinoff B, Linnoila M (1988). Acting out hostility in normal volunteers: negative correlation with levels of 5-HIAA in cerebrospinal fluid. Psychiatry Res 24: 187-194.

Sabol SZ, Hu S, Hamer D (1998). A functional polymorphism in the monoamine oxidase A gene promoter. Hum Genet 103: 273-279.

Smeraldi E, Zanardi R, Benedetti F, Di Bella D, Perez J, Catalano M (1998). Polymorphism within the promoter of the serotonin transporter gene and antidepressant efficacy of fluvoxamine. Mol Psychiatry 3: 508-511.

Sramek JJ, Pi EH (1996). Ethnicity and antidepressant response. $M t$ Sinai J Med 63: 320-325.

Stanley M, Traskman-Benz L, Dorovini-Zis K (1985). Correlations between aminergic metabolites simultaneously obtained from human CSF and brain. Life Sci 37: 1279-1286.

Villalon CM, Saxena PR (1997). Serotonin receptors as cardiovascular targets. Drug Dis Today 2: 294-300.

Wagner GJ, Maguen S, Rabkin JG (1998). Ethnic differences in response to fluoxetine in a controlled trial with depressed HIVpositive patients. Psychiatr Serv 49: 239-240.

Williams RB (1994). Neurobiology, cellular and molecular biology, and psychosomatic medicine. Psychosom Med 56: 308-315.

Williams RB (1998). Lower socioeconomic status and increased mortality: early childhood roots and the potential for successful interventions. JAMA 279: 1745-1746.

Williams RB, Marchuk DA, Gadde KM, Barefoot JC, Grichnik K, Helms MJ et al (2001). Central nervous system serotonin function and cardiovascular responses to stress. Psychosom Med 63: 300-305.

Yoshida K, Ito K, Sato K, Takahashi H, Kamata M, Higuchi H et al (2002). Influence of the serotonin transporter gene-linked polymorphic region on the antidepressant response to fluvoxamine in Japanese depressed patients. Prog Neuropsychopharmacol Biol Psychiatry 26: 383-386. 